\title{
The importance of clinical practice supported by health assessment tools
}

\section{Rodrigo Galvão Bueno Gardona', Dulce Aparecida Barbosa"}

\author{
' Universidade Federal de São Paulo, Post-Graduate Program in Gastroenterology. São Paulo, Brazil. \\ "Associate Professor and Professor of the Department of Clinical and Surgical Nursing of the Paulista \\ School of Nursing, Universidade Federal de São Paulo. Director of Communication and Publications of the \\ Brazilian Nursing Association. Chief Editor of the Brazilian Journal of Nursing. São Paulo, Brazil.
}

How to cite this article:

Gardona RGB, Barbosa DA. The importance of clinical practice supported by health assessment tools. Rev Bras Enferm [Internet]. 2018;71(4):1815-6. DOI: http://dx.doi.org/10.1590/0034-7167-2018710401

The tools of assessment in clinical practice are tools capable of objectively identifying important physical and psychic and spiritual changes, examining subjective phenomena and regularly monitoring the progression, regression or stagnation of a health-disease state. Moreover, of creating a steering mechanism for the examiner and the care team. These tools are still capable of standardizing conducts to be applied in each situation. Another important function is the epidemiological use they naturally bring. The most frequent data used comes from tools and this is because they are able to accurately extract data that often reflects a considerable public health problem.

The use of these resources in daily practice does not provide only clinical benefits, but also certainty regarding the reliability of the tool in question; since, before they are applied, they undergo different validation and accuracy procedures when it comes to diagnostic means.

The main tools of assessment are built by theoretical frameworks that support the constructs and are validated through rigorous and sophisticated statistical testing, which aim to reduce the uncertainty about the diagnosis that tools propose.

Tools of a different clinical nature may be cited, such as the Apgar score, the Glasgow scale, pain scales such as the Wong Baker Faces Pain or the Visual Analogue Scale, self-care assessment tools, scale to assess the severity of patients in intensive care units (the APACHE score) and the SOFA score, currently able to give the diagnosis of sepsis ${ }^{(1-2)}$.

These tools have in common the ability to generate, in a cohesive way, data on the probable state of health of someone or a situation. Tools offer a language that, according to the result of the score, is a translation of organic suffering or signs of risk.

The use of these resources organizes communication between the health team, which has a direct impact on the priority and logistics of care and the dimensionality of time.

Considering that the use of tools can also organize team dimensioning, an tool with predictive capacity is The Therapeutic Intervention Scoring System (TISS) ${ }^{(3)}$. It has stood out as a system that classifies the severity of the patient case, quantifying therapeutic interventions of medical and nursing procedures used. TISS starts from the premise that the greater the number of procedures, the greater the severity of the patient and, consequently, the greater donation of the health team for this patient. Therefore, this tool generates predictability, which is extremely important in the care routine.

Improving and securing communication between teams is another value of these tools. However, when a team does not know and ignores such applicability, acting in a disorganizing way, what was to be beneficial becomes isolated and useless. To clarify that, a situation in which the patient was in an induced coma is mentioned and a professional who was familiar with the use of tools wrote in the patient's chart: Ramsay score equal to 5 . When observing this score, it is understood that the patient's condition is actually severe with a shady prognosis, often imposing an immediate review of the care process ${ }^{(4)}$.

A score identifies a real or potential problem, given that it can focus resources and attention on its outcome. 
It is important to note once again that behind the use of tools or scales, there is a vast history of scientists who have worked hard to make possible methods that would translate objectively and quickly the condition of vulnerability of a patient.

Moreover, the Ministry of Health (Ministério da Saúde) has in its recommendations for prevention of pressure injury that, upon receiving the patient, one of the first actions to be taken in the admission process is the use of an tool to stratify the risk of developing ulcers. This score would therefore be the guiding principle for preventive actions. This score has a great value to what concerns the prevention of the illness and the safety of hospitalized patients.

Besides the clinical application within the hospital setting, it is necessary to look at another scenario in which these tools are also of great use.

For a long time, validating and actually using tools that assess, for example, the quality of life, hope, religiosity and spirituality, the feeling of impotence was despised and criticized among researchers of diverse areas. The main argument is that such information was of no scientific and clinical importance. However, today, such statements have been constrained by concerns that reflect the major current health scenarios: elderly people with increased life expectancy, and people in a state of palliative care.

A classic citation regarding this concern is the discussion of the surgical team in evaluating which surgical technique within myocardial revascularization brings more impact on the patient's quality of life: cardiopulmonary bypass (CPB) or non-CPB. Another common question is: does the use of hip prostheses improve the quality of life of patients when compared to the group with conservative treatment?

The reason for sustaining clinical practice using tools is justified by the range of benefits they bring to daily routine. They do not at any time nullify or encroach the human factor. It is precisely the opposite of it: they offer attributes that are closely considered in clinical reasoning, in the therapeutic plane or, rather, in the action plan.

For the use of tools such as tools and scales to become commonplace and continuous, it is first necessary to observe that they undergo an intense and judicious process of validation so that the information obtained is, in fact, coherent. That is: we must believe their effectiveness and efficiency.

Therefore, the importance of a tool-supported practice is focused on identifying its main capabilities and exposing, predicting, guiding and organizing them.

\section{REFERENCES}

1. Keegan MT, Soares M. What every intensivist should know about prognostic scoring systems and risk-adjusted mortality. Rev Bras Ter Intens [Internet]. 2016[cited 2018 May 21];28(3):264-9. Available from: http://www.scielo. br/pdf/rbti/v28n3/en_0103-507X-rbti-28-03-0264.pdf

2. Singer M, Deutschman CS, Seymour CW, Shankar-Hari M, Annane D, Bauer M, et al. The Third International Consensus Definitions for Sepsis and Septic Shock (Sepsis-3). JAMA [Internet]. 2016[cited 2018 May 21];315(8):80110. Available from: https://www.ncbi.nlm.nih.gov/pmc/articles/PMC4968574/

3. Perão OF, Bub MBC, Rodriguez AH, Zandonadi GC. The severity of patients' conditions and the nursing workload in an intensive care unit. Cogitare Enferm[Internet]. 2014[cited 2018 May 21];19(2):261-8. Available from: https:// revistas.ufpr.br/cogitare/article/view/33750/22733

4. Nagimar T, Serap K, Esra AT, Özgül O, Can OA, Aysel A, et al. The correlation among the Ramsay sedation scale, Richmond agitation sedation scale and Riker sedation agitation scale during midazolam-remifentanil sedation. Rev Bras Anestesiol[Internet]. 2017[cited 2018 May 21];67(4):347-54. Available from: http://www.scielo.br/pdf/ rba/v67n4/0034-7094-rba-67-04-0347.pdf 